\title{
Setting the Foundation for Effective Learning: Utilizing the Cognitive, Affective, and Psychomotor Domains to Establish Rigorous Performance Learning Objectives in Postsecondary Aviation Programs
}

\author{
Jeffrey A. Johnson \\ Aviation Institute \\ University of Nebraska at Omaha \\ and \\ Michael D. Ferguson \\ Department of Geography \\ Bowling Green State University
}

\begin{abstract}
Institutions of American higher education have become increasingly scrutinized by governmental agencies, organizations, and the public (Wingspread Group on Higher Education, 1993). Accountability to these constituents has presented itself as a unique challenge to higher education. Greater accountability has also manifested an increased demand for effective assessment programs (Banta, Lund, Black, \& Oblander, 1996). Accountability and assessment have undoubtedly emerged into postsecondary aviation as well. Consequently, aviation programs must continually justify their existence in providing a highly needed and important resource to society by preparing well-educated and skilled graduates for the workplace. If credible assessment programs reveal problems in educational outcomes, then likely candidates for review are the performance learning objectives in the classroom.

The authors present the argument that rigorous, well-developed performance learning objectives provide the underlying foundation for effective learning. The importance of establishing clearly stated, specific performance learning objectives and its relationship to the learning environment are also discussed. Effective performance learning objectives will not only enhance student learning experiences in the aviation classroom, but will favorably affect program strength and ultimately, institutional effectiveness.
\end{abstract}

\section{Introduction}

In a fast-paced society where many aviation students have greater opportunities to learn in high technological classroom environments, perhaps nothing can be more frustrating for students to encounter than vague, poorly written, or in some instances, non-existent performance learning objectives. Students who manage to complete aviation courses with substandard or, at best, an average comprehension of the course material, may encounter substantial difficulties in 
applying knowledge across academic interdisciplinary lines as well as incorporating practical application of basic aeronautical knowledge in their chosen professions. Even worse, some studies (Wingspread Group on Higher Education, 1993; the National Adult Literacy Survey, 1993) have indicated that despite technological innovations and advances, an increasing number of students are unprepared to meet the requirements of daily life such as using basic skills involving reading, writing, and elementary problem-solving. This finding strongly suggests that the widespread evaluation, enhancement, and implementation of clear performance learning objectives is not only timely, but very necessary.

Technology undoubtedly plays an increasingly important role in student learning. In a study conducted by Witiw and Kelly-Benjamin (1997), the researchers found that students' knowledge of basic aviation meteorology increased significantly in a technologically advanced aviation meteorology course. However, the most technologically advanced equipment in the classroom should neither be used as a replacement for rigorous performance learning objectives nor should be relied upon by faculty as an adequate substitute for effective educational outcomes. Developing rigorous performance learning objectives is paramount and should be inconsequential to the faculty member's decision to incorporate high technological equipment in assisting instructional delivery.

Developing clear learning objectives has many advantages for students. According to Renner (1993), the student gains a better understanding of the instructor's expectations and the instructor can actually see the subject matter that has to be taught. This will subsequently allow for the concise promulgation of course objectives to the students. Student confusion and frustration can be substantially limited or eliminated altogether, making the learning experience an enjoyable process.

Clear learning objectives also provide the instructor with a precise roadmap necessary for the instructional process to progress steadily and with coherence throughout the duration of the course. Unnecessary duplication of instruction can be drastically reduced if not eliminated altogether. Clear learning objectives also provide students with a necessary roadmap to navigate confidently through the course expectations in a progressive, coherent manner and may subsequently enhance the students' overall course knowledge retention level. This factor becomes highly significant when challenging students' basic problem-solving abilities in the classroom and should be a fundamental

part of every aviation students' acquired academic skills. Thus, the educational expectations and criteria can ill-afford to be ambiguous.

\section{Foundational Issues in Developing Performance Learning Objectives}

Research has indicated that many college campuses invest too much effort in establishing credentials for their students to achieve, often at the expense of assessing knowledge, skills, and competencies (Wingspread Group on Higher Education, 1993). Establishing specific performance learning objectives in the classroom is of paramount importance in laying the underlying foundation for student learning. This, inevitably, will enhance the credentials students are working towards acquiring.

By utilizing the cognitive, affective, and psychomotor performance objective domains from Bloom $(1956,1973)$ to facilitate the development of specific learning objectives, educators can enhance the overall quality and effectiveness of their instructional materials. Renner (1993) 
more recently described Bloom's three performance objective domains in the form of teaching points that educators can use to address learners' needs by challenging the learner to (a) recall, recognize or expand knowledge (cognitive domain), (b) develop attitudes, feelings, values, or appreciations (affective domain), and (c) acquire skills involving tools, procedures, and techniques (psychomotor domain).

Addressing the three teaching points in the aviation classroom is crucial. The aviation industry is encountering profound growth and change (Kaps \& Ruiz, 1997). In order to maintain the academic readiness that must necessarily accompany these changes, aviation educators need to continually strive to challenge student learning through new and innovative educational methods. Thus, the implementation of specific performance learning objectives within the classrooms of postsecondary aviation may provide educators the means to much more accurately discover, launch, and perfect new teaching methods through experimentation. This could prove to be mutually beneficial to both the educator and student. The student would have the advantage of accurately portraying the instructor's expectations of academic performance within the class, which in turn, may enable the student to more effectively set and achieve academic goals on an individual basis. The educator has the advantage of being able to establish a more effective baseline of expected academic performance which can be utilized to measure student progress.

\section{The Importance of Appropriate Terminology Usage}

The intelligible usage of subject specific terminology is perhaps as important as cognizance of the three learning domains when creating or revising curricula. When the objectives of the course are ambiguous or not clearly delineated, confusion may result that could prove to be an academic detriment to the student. Thus, it is imperative that educators take the responsibility and initiative in the deliberate selection of appropriate terminology in the development of clear and effective performance learning objectives. By doing so, educators can ensure that students will be able to determine exactly what is expected of them in the classroom, a situation that is paramount for student academic success.

In order for students to determine exactly what is expected of them in the classroom, educators need to select appropriate terminology in developing clear and effective learning objectives. For example, words such as know, appreciate, and understand are vague and provide an avenue for widespread interpretation unlike more precise words such as analyze, define, describe, list, and repair (American Center Association for Vocational Instructional Materials, 1977). In developing clear performance learning objectives, Table 1 contrasts the differences in using vague terms versus specific terms. 
Table 1

Terminology Usage Comparisons

\begin{tabular}{ll}
\hline Vague & Specific \\
\hline
\end{tabular}

1. know the atmospheric conditions ideal for airframe icing

2. develop an appreciation for ideal conditions conducive to ice formation

3. understand how to respond to ice formation
1. identify two atmospheric conditions ideal for airframe icing

2. analyze the conditions conducive to ice formation

3. implement corrective action in response to ice formation 
In Table 2, an illustration is provided that incorporates a specific performance learning objective for students enrolled in an aviation meteorology course followed by a discussion of each learning domain. The specific terms illustrated in Table 1 were incorporated into the learning objective exemplified in Table 2.

Table 2

\section{Topic: Aircraft Structural Icing}

Learning Objective: Given the appropriate equipment and materials, the student will be able to correctly identify two main types of aircraft structural icing, analyze the conditions which are conducive to the formation of icing and implement corrective action in response to ice formation.

\section{Teaching Points}

Knowledge (Cognitive Domain)

*Two conditions ideal for icing:

1. flying in visible precipitation, and

2. temperature is $0^{\circ}$ Celsius or colder.

*Rime ice:

rough, milky, opaque ice formed by the instantaneous freezing of small supercooled water droplets.

*Clear ice: glossy, clear, or translucent ice formed by the relatively slow freezing of large supercooled water droplets.
Attitude (Affective Domain) (Psychomotor Domain)

Skill

* Remain extra alert

\begin{tabular}{|c|c|}
\hline $\begin{array}{l}\text { *Remain extra alert } \\
\text { when encountering } \\
\text { icing conditions }\end{array}$ & $\begin{array}{l}\text { *How to avoid } \\
\text { icing conditions. }\end{array}$ \\
\hline $\begin{array}{l}\text { *“Aircraft structural ice } \\
\text { can be inherently } \\
\text { dangerous to safe flight.” }\end{array}$ & $\begin{array}{l}\text { *How to deviate } \\
\text { out of icing } \\
\text { conditions. }\end{array}$ \\
\hline $\begin{array}{l}\text { *“Substantial ice build- } \\
\text { up could kill me (us).” }\end{array}$ & $\begin{array}{l}\text { *How to use de-ice } \\
\text { anti-ice equipment } \\
\text { (if applicable). }\end{array}$ \\
\hline $\begin{array}{l}\text { *"The safety of the air- } \\
\text { craft and its occupants } \\
\text { in icing conditions is } \\
\text { my responsibility and my } \\
\text { highest priority!” }\end{array}$ & $\begin{array}{l}\text { *How to develop } \\
\text { a smooth and } \\
\text { consistent flow } \\
\text { check for encoun- } \\
\text { tering icing con- } \\
\text { ditions. }\end{array}$ \\
\hline
\end{tabular}

Note. Knowledge (Cognitive Domain) teaching points are definitions from the Aeronautical Information Manual (p. 7-1-22, 23), by the AOPA Air Safety Foundation, 1997, Pittsburgh, PA: Superintendent of Documents. 


\section{The Cognitive Domain}

Educators need to effectively integrate learning strategies into all three learning domains to enhance the learning experience. In evaluating the three teaching points, educators have historically placed great emphasis on cognitive domain learning with little or no emphasis on the affective and psychomotor domains. This is highly significant as Bloom (cited in Anderson \& Sosniak, 1994) argued that even though information or knowledge is an important educational outcome, few educators would view this as the primary or sole outcome of instruction. This predication by Bloom continues with the assertion that some evidence is needed to show that students can apply the knowledge that they have gained to practical situations and problem solving. To further complicate matters, some researchers argue that educators have even failed to address strong knowledge-based areas (i.e., the cognitive domain) as Freire (1971) stated that "students are not called upon to know but to memorize the contents narrated by the teacher. Nor do the students practice any act of cognition, since the object towards which that act should be directed is the property of the teacher” (pp. 67-68).

Despite substantial teaching emphasis on the cognitive domain, some studies (Daggett, 1995; Wingspread Group on Higher Education, 1993) have indicated that students are having problems in knowledge application. In charting Bloom's cognitive model to an application model, Daggett (1995) found weaknesses in students' abilities to effectively apply knowledge across disciplinary boundaries and to predictable/unpredictable situations (see Figure 1). According to Daggett (1996) in a more recent study, "America may do well in the world in teaching the upper levels of Bloom's; this does not mean, however, that students are able to translate that high-level instruction into real-world applications” (p. 9). For the aviation meteorology student, Daggett's argument can easily be assimilated. For example, memorizing two types of aircraft structural icing for an examination may not prove to be difficult. However, memorization of material for an examination does not mean the student has the ability to use the practical application of knowledge in specific situations. Simple memorization of material is neither a guarantee of academic success, nor is it a true measure of an individual student's subject knowledge retention level. This factor presents challenges in the academic environment that are unique, but by no means insurmountable. The establishment of strong knowledge-based principles in the cognitive domain will prove to be beneficial to students, particularly when applying these skills through psychomotor and affective activities to unpredictable/unfamiliar situations. 


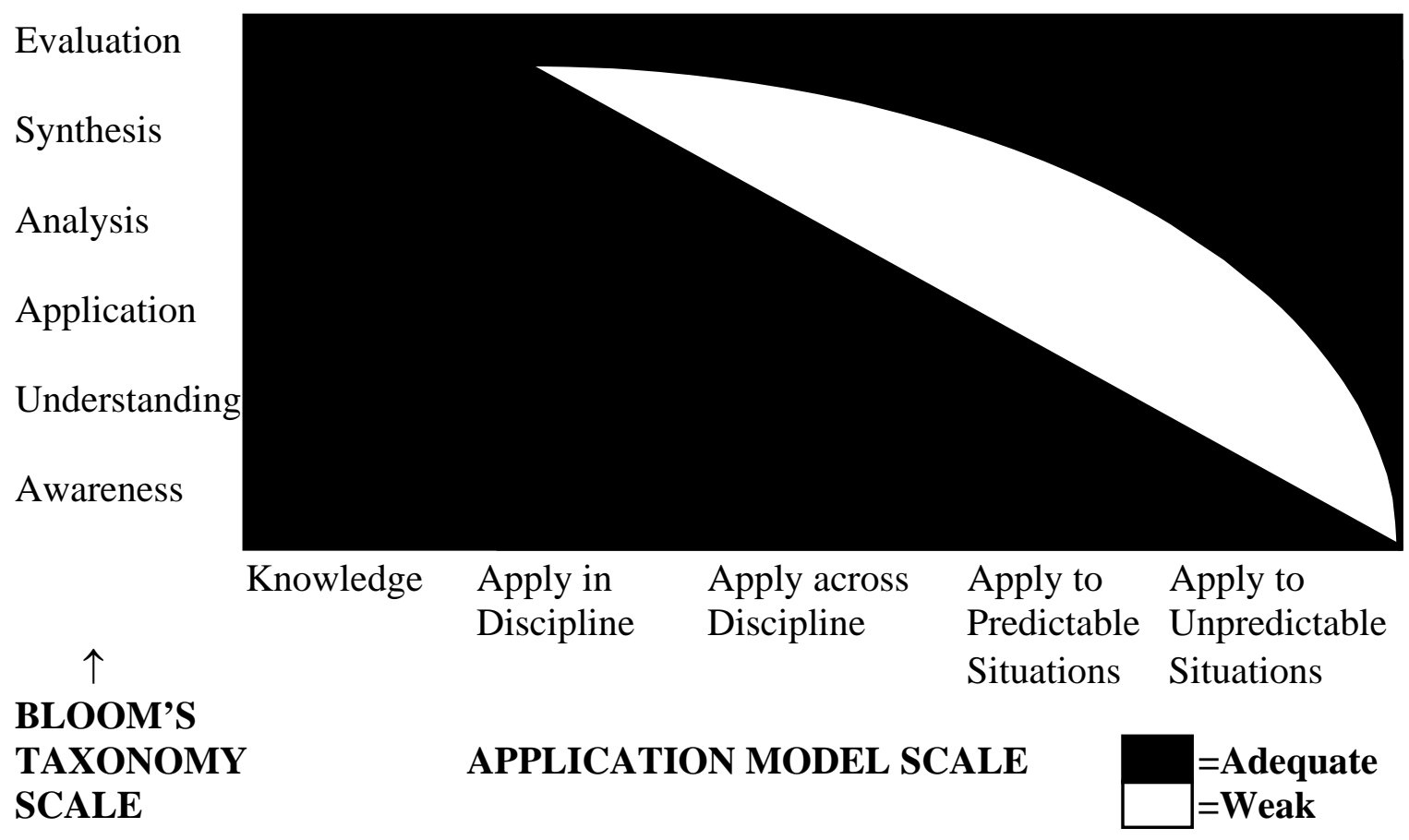

Figure 1. Weak areas of student learning in Bloom's cognitive domain across an application model. From Testing and Assessment in American Schools-Committing to Rigor and Relevance (1995) by W. R. Daggett.

\section{The Affective Domain}

Perhaps the most difficult aspect of teaching lies in the students' affective domain. Bloom (1956) stated that "objectives in this domain are not stated very precisely; and, in fact, teachers do not appear to be very clear about the learning experiences which are appropriate to these objectives” (p. 7). According to Paul (1985), not all learning is rational and the process that leads to a belief or a change in belief may be more important than belief itself. Educators can influence student behavior through positive or negative experiences, but what about changing their beliefs or preconceived attitudes regarding specific subject matter? Challenging students to rethink their values and revisit their behavioral reactions to situations in a process over time may provide instructors with an effective means to influence affective domain behavior and make rational assessments of student progress.

The aviation meteorology student's affective behavior may not exhibit "more alertness" during icing conditions or for that matter, may not exhibit any type of concern at all. According to Bloom (1973), an individual is more apt to achieve a "readiness to revise judgments and to change behavior in the light of evidence” (p. 183). In the case of the aviation meteorology student, the "light of evidence" may be a newfound belief that death becomes a realistic possibility from uncontrolled structural ice buildup as a result of a real life experience, 
simulation, or classroom based discussion. This, invariably, may be sufficient enough to change behavior within the affective domain.

Less dramatic than a real life close encounter with death, academic exercises such as role playing provide learners with the opportunity to try out new behaviors in a controlled setting. This also provides the instructor with a unique opportunity to observe student attitudes and subsequent responses to controlled, yet changing situational stresses. For example, a flight simulation provides a learning environment controlled by the instructor and the implementation of affective performance learning objectives of the course can be viewed by the instructor while being experienced firsthand by the student. This also provides the instructor with the invaluable opportunity to vividly illustrate the importance of aviation safety to the student as an integral part of the overall learning objectives, which carries with it the possibility of reinforcing positive situational attitudes within the affective domain of the student.

\section{The Psychomotor Domain}

Although Bloom (1956) recognized the existence of the psychomotor domain, he argued that developing a classification for these objectives would not have been useful. However, Harrow (1972) developed a working and useful taxonomy for the psychomotor domain to address the concerns of educators who deal primarily in the psychomotor domain. The purpose of Harrow's taxonomy is to assist educators in building skillful and efficient execution of movement tasks and patterns in natural locomotor, non-locomotor, and manipulative movements. Harrow observed that the modern educational system has the potential to help students by providing them with meaningful, sequentially organized movement activities. Educational concepts such as these harbor many potential benefits for the aviation student because a great deal of aviation related tasks are highly dependent on the proficient execution of tasks that lie within the psychomotor domain.

Although some of the skills in the psychomotor domain may appear outwardly simple, some psychomotor skills can become extremely complex, particularly when incorporating other learning behaviors into psychomotor skills. Harrow (1972) argued that when purposeful movement is being executed, a person is coordinating the cognitive, psychomotor, and affective domains. For example, regarding the psychomotor skill how to use de-ice/anti-ice equipment, a student elects to move a switch or a series of switches to activate the equipment at a given point in time. The event is predicated on the student using cognitive domain behaviors to determine when atmospheric conditions are conducive to the utilization of de-ice/anti-ice equipment and affective domain behaviors to determine that the current buildup of structural ice is inherently dangerous to safe flight.

A simplified illustration of a psychomotor skill for using de-ice/anti-ice equipment involves the utilization of a flow check through a basic simulation exercise. For example, the student who is developing a psychomotor skill in the application of proper operating procedures in employing anti-ice may start at the overhead panel from left to right, work diagonally, and then from left to right in a Z-pattern. In itself, the flow check does not necessarily require the student to utilize knowledge or exhibit some type of behavior (attitude). However, by physically "motioning" through operating procedures, the student's psychomotor skills are further developed in successfully implementing corrective action in a timely and efficient manner in 
response to the formation of aircraft structural icing.

Regarding the implementation of strong performance learning objectives within the psychomotor domain, Harrow (1972) affirms that the psychomotor domain is purported by many educators to be the easiest of the three domains for writing specific educational objectives because psychomotor behaviors for the most part, can be observed and measured. Therefore, the importance of the psychomotor domain and its relationship to effective educational outcomes in the postsecondary aviation learning environment should not be underestimated.

\section{Teaching Points in Various Domains}

Elements initially found in one domain often contain teaching points that encompass other domains. Renner (1993) provided an example by pointing out that some behaviors, such as avoiding injuries within a given learning objective, are an attitude and a skill. The psychomotor skill how to avoid icing conditions is predicated on the student's ability to analyze the two conditions ideal for icing in the cognitive domain and to implement corrective action accordingly. Affective domain behaviors such as remaining extra alert when encountering icing conditions will invariably play a role in the implementation of corrective action as well. Specific psychomotor skills such as changing power settings, altitudes, and airspeed also requires a cognitive awareness of identifying specific numbers from the pilot's operating handbook.

By incorporating Bloom's learning domains and Renner's teaching points, aviation educators can develop scenarios involving unpredictable events that challenge students' abilities. The example presented in Table 2 can be used by educators as a platform to develop specific performance learning objectives covering the three learning domains. From the illustration how to deviate out of icing conditions in an unforecast weather situation, psychomotor skills will also require students to exercise knowledge (cognitive domain) by knowing the ideal conditions for structural icing.

\section{Conclusions}

Technology cannot replace strong performance learning objectives in the classroom. Effective learning outcomes are paramount if educators expect to communicate their expectations to students in a clear and concise manner. Simply learning the material from a class provides unique challenges for most students without burdening them to decipher the meanings of weak or non-existent performance learning objectives. Utilizing state of the art equipment to deliver instructional materials to students should be used to complement, not replace effective performance learning objectives.

Educators need to be aware of the three learning domains and how they interrelate. Traditionally, assessment programs have revealed that educators have focused primarily on the cognitive domain at the expense of the affective and psychomotor domains (Banta, Lund, Black, \& Oblander, 1996). Challenging students to rethink their values and behavioral reactions to situations over time has the potential of providing a very positive and rewarding learning experience. Establishing effective performance learning objectives is imperative in providing the necessary tools for students to successfully navigate through entire courses and academic programs. This, in turn, will provide an avenue for assisting students in meeting the ultimate 
challenge that lies ahead after graduation-facing unpredictable situations in careers and life itself.

\section{References}

Aeronautical information manual (1997). Pittsburgh, PA: Superintendent of Documents. American Center Association for Vocational Instructional Materials. (1977). Learning experience I. Athens, GA: University of Georgia.

Anderson, L. W., \& Sosniak, L. A. (1994). Bloom’s taxonomy: A forty-year retrospective. Chicago: The National Society for the Study of Education.

Banta, T. W., Lund, J. P., Black, K. E., \& Oblander, F. W. (1996). Assessment in practice: Putting principles to work on college campuses. San Francisco: Jossey-Bass.

Bloom, B. S. (1956). Taxonomy of educational outcomes: Vol. I. Cognitive domain. White Plains, NY: Longman.

Bloom, B. S. (1973). The taxonomy of educational objectives: Affective and cognitive domains. New York: David McKay, Inc.

Daggett, W. R. (1995). Testing and assessment in American schools-committing to rigor and relevance. Schenectady, NY: International Center for Leadership in Education, Inc.

Daggett, W. R. (1996, April). The challenge to American schools: Preparing students for the 21st century. School Business Affairs, 5-13.

Freire, P. (1971). Pedagogy of the oppressed. New York: Seaview.

Harrow, A. J. (1972). A taxonomy of the psychomotor domain: A guide for developing behavioral objectives. New York: David McKay, Inc.

Kaps, R. W., \& Ruiz, J. R. (1997, September). Educational requirements for a career in airline management: An industry perspective. Collegiate Aviation Review, 43-57.

National adult literacy survey. (1993). Princeton, NJ: Educational Testing Service.

Paul, R. W. (1985). Bloom's taxonomy and critical thinking instruction. Educational Leadership, 42(8), 36-39.

Renner, P. (1993). The quick instructional planner. Vancouver, BC: Training Associates Ltd.

Wingspread Group on Higher Education. (1993). An American imperative: Higher expectations for higher education. Washington, DC: The Johnson Foundation, Inc.

Witiw, M. R., \& Kelly-Benjamin, K. (1997, September). Student performance in a technologically-enhanced meteorology course. Collegiate Aviation Review, 33-42. 